Full length article

\title{
Performance of waste based alkaline mortars submitted to accelerated carbon dioxide curing
}

\author{
M. Mastali ${ }^{\mathrm{a}}$, Z. Abdollahnejad ${ }^{\mathrm{a}}$, F. Pacheco-Torgal ${ }^{\mathrm{a}, \mathrm{b}, *}$ \\ a C-TAC Research Centre, University of Minho, Guimarães, Portugal \\ b SHRC, University of Sungkyunkwan, Suwon, Republic of Korea
}

\section{A R T I C L E I N F O}

\section{Keywords:}

Carbon dioxide sequestration

Fly ash

Waste glass

Compressive strength

Elastic modulus

Drying shrinkage

\begin{abstract}
A B S T R A C T
Carbon dioxide sequestration is crucial for targets limiting global warming could be achieved. This paper discloses results of an investigation concerning the performance of fly ash/waste glass alkaline-based mortars with two additives and recycled aggregates exposed to accelerated carbon dioxide curing. Mechanical properties as well as water absorption, drying shrinkage and carbon sequestration potential were studied on it. The results show that the mixtures with calcium hydroxide and sodium hydroxide concentration of $8 \mathrm{M}$ leads to the highest compressive strength (10 MPa) which is high enough for the production of masonry blocks. Significant correlations between the flexural strength and the compressive strength were noticed. The mixtures show a low water absorption by immersion $(9 \%)$ as well as by capillary $\left(1.4 \mathrm{~kg} / \mathrm{m}^{2} \mathrm{H}^{0.5}\right)$. The results of the modulus of elasticity show that increasing the sodium hydroxide molarity increased the stiffness of the mixtures. The results of drying shrinkage are in line with the results of the capillary water absorption and of the elastic modulus. A maximum $\mathrm{CO}_{2}$ sequestration $\left(164 \mathrm{kgCO}_{2} \mathrm{eq} / \mathrm{m}^{3}\right.$ ) is noticed for the mixture with a sodium concentration of $8 \mathrm{M}$ based on the additive calcium hydroxide.
\end{abstract}

\section{Introduction}

Carbon dioxide sequestration is crucial for targets limiting global warming could be achieved (Hansen et al., 2017). That is why carbon sequestration constitutes one of the Grande Challenges of Engineering (Mote et al., 2016). Currently this carbon sequestration is carried out mostly through geologic $\mathrm{CO}_{2}$ storage in saline aquifers (Zhang and Huisingh, 2017). However, that constitutes a passive strategy has large risks and also has a very high cost. Carbon capture and storage at fossil fuel burning sites like power plants or steel plants is a more efficient process and thus less expensive than direct air capture (Hansen et al., 2017). Several authors (Jang et al., 2016) have studied the use of $\mathrm{CO}_{2}$ as accelerated curing of cementitious constructions materials. This technology will in future prevent carbon dioxide to be released into the atmosphere but it will also accelerate curing and strength development of those materials. However, so far no studies regarding carbon sequestration were performed on alkali activated based materials. Fig. 1 shows the classification of different subsets of these materials (Van Deventer et al., 2010). Alkali activated materials have a particular ability for the reuse of several types of wastes (Bernal et al., 2016). Waste use is a crucial issue in the European context of a circular economy and zero waste target (Bontempi, 2017a,b). Some wastes like fly ash deserve an especial attention because they are generated in high amount and have a very low reuse rate (Huang et al., 2016). USA has a reuse rate for fly ash of around 50\% meaning that 30 million tons of fly ash are not reused annually (ACAA, 2016). Helping to explain the efforts of the scientific community concerning its valorization (Poinot et al., 2018). The high volume of construction and demolition wastes (CDW) also constitutes a serious problem. Eurostat estimates the total for Europe of around 1000 million tons/year, representing an average value of almost 2.0 ton/per capita. The reuse of CDW as recycled aggregates not only constitutes a way to give value to a waste but also prevents the use of river sand (Pacheco-Torgal et al., 2013; Ioannidou et al., 2017). Waste glass is also a waste that is generated in relevant quantities and that merits increase recycling efforts (Hossain et al., 2016; Torres-Carrasco and Puertas, 2017). This paper presents results of an investigation concerning carbon dioxide sequestration on fly ash/ waste glass alkaline-based mortars with recycled aggregates.

\section{Experimental program}

\subsection{Materials}

The mortars were made of fly ash (FA), calcium hydroxide $(\mathrm{CH})$,

\footnotetext{
* Corresponding author at: C-TAC Research Centre, University of Minho, Guimarães, Portugal.

E-mail address: torgal@civil.uminho.pt (F. Pacheco-Torgal).
} 


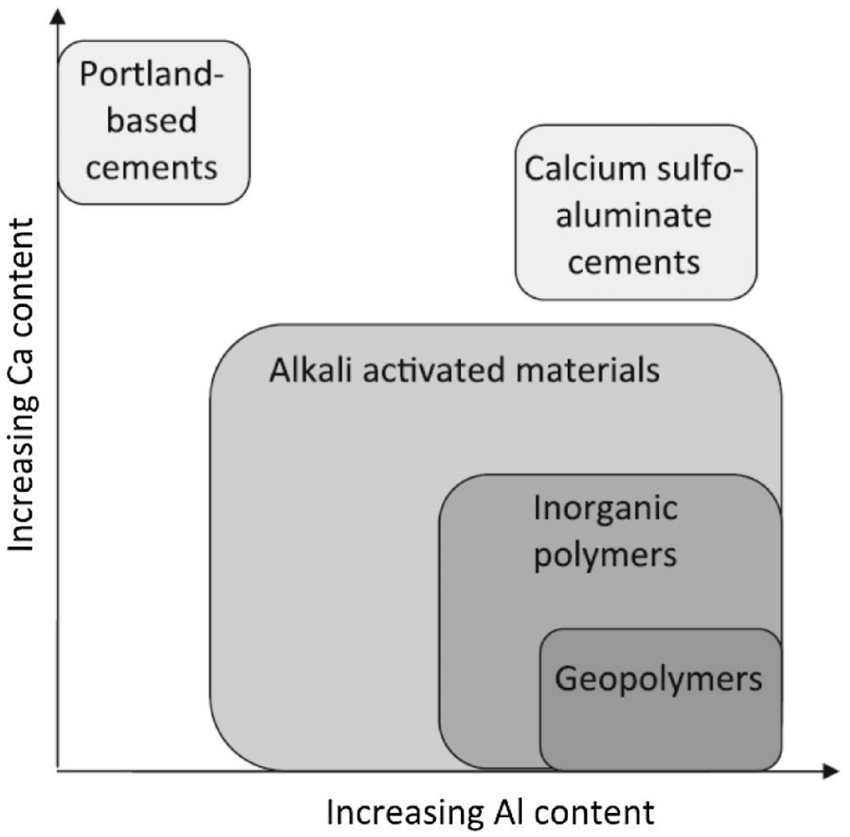

Fig. 1. Classification of different subsets of alkali activated materials with comparisons to OPC and calcium sulfoaluminate binder chemistry (Van Deventer et al., 2010).

Table 1

Chemical composition of major oxides in fly ash.

\begin{tabular}{lllllllll}
\hline Material & \multicolumn{1}{l}{ Oxides (wt.\%) } \\
\cline { 2 - 8 } & $\mathrm{SiO}_{2}$ & $\mathrm{Al}_{2} \mathrm{O}_{3}$ & $\mathrm{Fe}_{2} \mathrm{O}_{3}$ & $\mathrm{CaO}$ & $\mathrm{MgO}$ & $\mathrm{Na}_{2} \mathrm{O}$ & $\mathrm{K}_{2} \mathrm{O}$ & $\mathrm{TiO}_{2}$ \\
\hline Fly Ash & 60.81 & 22.68 & 7.64 & 1.01 & 2.24 & 1.45 & 2.7 & 1.46 \\
\hline
\end{tabular}

waste glass (MG), ordinary Portland cement (PC), recycled aggregates and a sodium hydroxide solution. The fly ash was obtained from The PEGO Thermal Power Plant in Portugal that uses coal as fuel being categorized as class B and group N regarding the ASTM C618-15 (ASTM C618-15, 2015). Table 1 presents the major oxides of fly ash particles and was obtained with EDS analysis. The Portland cement is of type I class 42.5R from SECIL, its composition contains $63.3 \% \mathrm{CaO}, 21.4 \%$ $\mathrm{SiO}_{2}, 4.0 \% \mathrm{Fe}_{2} \mathrm{O}, 3.3 \% \mathrm{Al}_{2} \mathrm{O}_{3}, 2.4 \% \mathrm{MgO}$ and other minor components. The calcium hydroxide was supplied by LUSICAL H100 and contain more that $99 \% \mathrm{CaO}$. Waste glass from glass bottles ground for one hour in a ball mill was also used. The final density of the milled waste glass was $1.27 \mathrm{~g} / \mathrm{cm}^{3}$. Solid sodium hydroxide was supplied by ERCROS, S.A., Spain, and was used to prepare the $\mathrm{NaOH}$ solution with three different concentrations $7 \mathrm{M}, 8 \mathrm{M}$ and $9 \mathrm{M}$. Distilled water was used to dissolve the sodium hydroxide flakes. This was done to avoid the effect of unknown contaminants in the tap water. The $\mathrm{NaOH}$ mix was made $24 \mathrm{~h}$ prior to use in order to have a homogenous solution at room temperature. A recycled sand to binder ratio of 4 was used in all the mixtures. The recycled sand was obtained from the crushing of concrete blocks were also used after having being sieved. The average compressive strength of concrete blocks was around $40 \mathrm{MPa}$. A sieving operation was carried out to remove dust particles. It was dried at $105^{\circ} \mathrm{C}$ for $24 \mathrm{~h}$ and it was sieved in advance before being used. The dimension of the sieves was $4.75 \mathrm{~mm}$ and $0.6 \mathrm{~mm}$. The recycled sand has a fineness modulus of 3.885. The detailed grain size distribution of the recycled sand are presented in Fig. 2. The recycled sand has a water absorption of $13 \%$. Before use the recycled sand was carbonated in a carbon a chamber from Aralab model Fitoclima $\mathrm{S} 600$ (4.2\% $\mathrm{CO}_{2}, 40 \%$ $\mathrm{RH}$, and $20^{\circ} \mathrm{C}$ ) during $48 \mathrm{~h}$. The recycled sand has a water absorption of $25 \%$. The explanation for the increase of the water absorption relates to the fact that the carbonation of CSH is associated to an increase of its porosity. Šavija and Luković (2016) showed that the decomposition of $\mathrm{C}-\mathrm{S}-\mathrm{H}$ involves in a first moment the calcium removal from the silicate chains while in a subsequent step it's the calcium from the principal layers that is removed.

\subsection{Mix design and mortar production}

The composition of the mortars is shown in Table 2. In the batching process of the mortars, dry ingredients (fly ash, recycled sand, calcium hydroxide (or cement), metakaolin, and milled glass) were mixed for $2 \mathrm{~min}$. Then, sodium hydroxide was added and again mixed for $3 \mathrm{~min}$. Then, the mixed mortars were cast into cubic molds $\left(50 \times 50 \times 50 \mathrm{~mm}^{3}\right)$ to assess the compressive strength and in prismatic beams with dimension $(40 \times 40 \times 160 \mathrm{~mm})$ to assess the flexural strength. The specimens were cured for $24 \mathrm{~h}$ at the lab conditions (averagely $25^{\circ} \mathrm{C}$ and $40 \% \mathrm{RH}$ ) and then they were demolded. Then the specimens were cured in the carbonation chamber $\left(4.2 \% \mathrm{CO}_{2}\right.$ concentration and $40 \% \mathrm{RH}$ ) for 7 days and curing in the lab conditions for the remaining days until the age of the test. This is because preliminary experiments showed that all mixtures were fully carbonated during 7 days through a $\mathrm{CO}_{2}$ preconditioning curing. Three specimens with dimension of $50 \times 50 \times 50 \mathrm{~mm}^{3}$ were casted and used to measure the $\mathrm{CO}_{2}$ sequestration by using a furnace decomposition method (El-Hassan and Shao, 2015). The carbonated specimens were placed initially in the oven at $105^{\circ} \mathrm{C}$ during $24 \mathrm{~h}$ to evaporate any absorbed water. Then, the weights of the dried specimens were recorded. Afterwards, the specimens were put in the calciner at a temperature between 500 and $850{ }^{\circ} \mathrm{C}$ during $4 \mathrm{~h}$ in order to measure the amount of water that is bound to hydration products and the amount of carbon dioxide in carbonates. The results revealed that $800{ }^{\circ} \mathrm{C}$ could be used as the appropriate decomposition temperature.

\subsection{Test procedures}

\subsubsection{Compressive strength}

The compressive strengths of the mixtures were assessed at different ages 7,14 , and 28 days. The compressive strength of each mixture was obtained by averaging the replicated three cubes. All cubic specimens were assessed under compressive load with a constant displacement rate of $0.30 \mathrm{~N} / \mathrm{mm}^{2} . \mathrm{s}$, based on the ASTM C109 recommendation (ASTM C109, 2016). The compressive load was measured with a load cell of $200 \mathrm{kn}$ capacity.

\subsubsection{Flexural strength}

Flexural performance was assessed under Three Point Bending load conditions, as indicated in Fig. 3. The flexural strength of each mixture was obtained by averaging the three specimens. The flexural load was applied to the beams with a displacement rate of $0.6 \mathrm{~mm} / \mathrm{min}$. The flexural load was measured with a load cell of $50 \mathrm{kn}$ capacity. Eq. (1) was used to calculate the flexural strength of specimens:

$\sigma_{f}=\frac{3 F L}{2 b h^{2}}$

where, $\mathrm{F}$ is the flexural load, $\mathrm{L}$ is the span length, $\mathrm{b}$ and $\mathrm{h}$ are width $(40 \mathrm{~mm})$ and height $(40 \mathrm{~mm})$ of the prismatic beams.

\subsubsection{Water absorption}

The water absorption by immersion method was based on three cubic specimens with a $100 \mathrm{~mm}$ edge per mixture. The specimens with age of 28 days were dried through at the temperature $105^{\circ} \mathrm{C}$.The specimens were then immersed in the water container at $23 \pm 2{ }^{\circ} \mathrm{C}$ until saturation of the specimens. Next, the specimens were submerged in water using a mesh container and the mass of the submerged specimen has been recorded as immersed mass (Wim). Then, the specimen was removed from the last position and its surface was cleaned using a wet cloth and immediately the weight of the specimens were measured as 


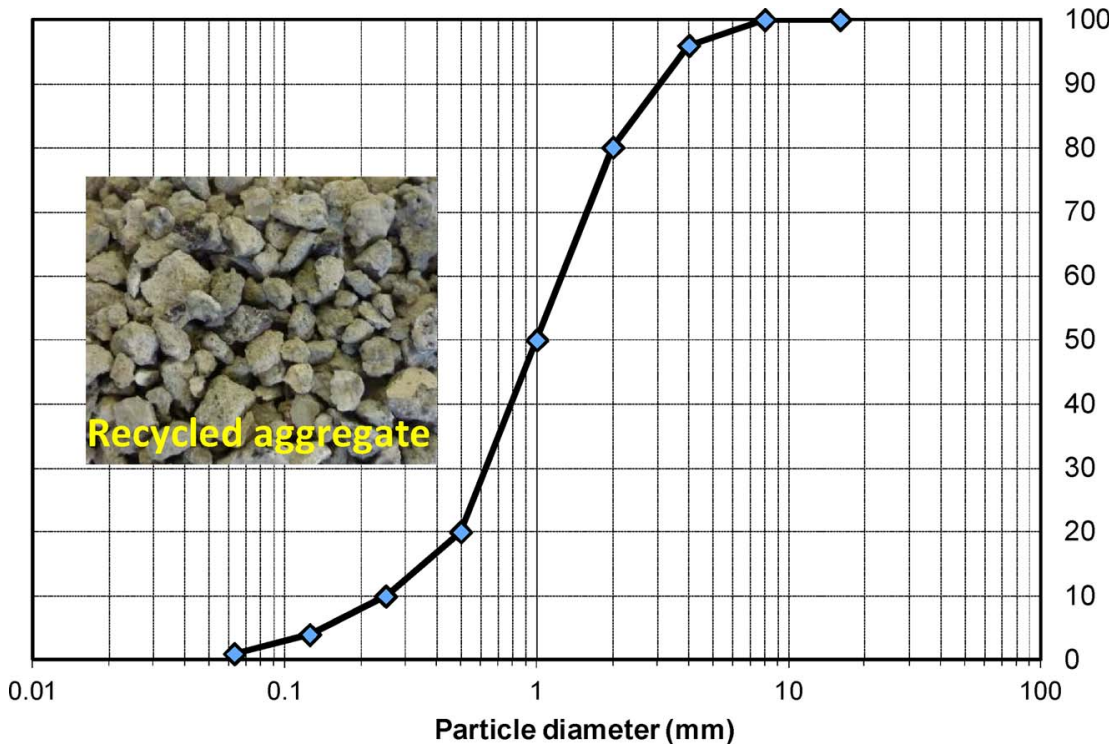

Fig. 2. Standard granulometry of recycled sand.

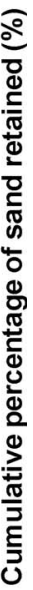

Table 2

Proportions of mix compositions $\left(\mathrm{kg} / \mathrm{m}^{3}\right)$.

\begin{tabular}{|c|c|c|c|c|c|c|c|}
\hline Mixtures & Fly ash & $\mathrm{CH}$ & PC & MG & SH & Sand & Molarity \\
\hline 80FA_10CH_10MG_RAGC_CC_7M & 340.0 & 42.5 & - & 42.5 & 215.5 & 1700.0 & $7 \mathrm{~mol} / \mathrm{L}$ \\
\hline 80FA_10PC_10MG_RAGC_CC_7M & 341.0 & - & 43.0 & 43.0 & 213.0 & 1706.0 & \\
\hline 80FA_10CH_10MG_RAGC_CC_8M & 340.0 & 42.5 & - & 42.5 & 215.5 & 1700.0 & $8 \mathrm{~mol} / \mathrm{L}$ \\
\hline 80FA_10PC_10MG_RAGC_CC_8M & 341.0 & - & 43.0 & 43.0 & 213.0 & 1706.0 & \\
\hline 80FA_10CH_10MG_RAGC_CC_9M & 340.0 & 42.5 & - & 42.5 & 215.5 & 1700.0 & $9 \mathrm{~mol} / \mathrm{L}$ \\
\hline 80FA_10PC_10MG_RAGC_CC_9M & 341.0 & - & 43.0 & 43.0 & 213.0 & 1706.0 & \\
\hline
\end{tabular}

FA-Fly ash, CH-Calcium hydroxide, PC-Portland cement, SH-Sodium hydroxide, MG-Milled glass, RAGC-Recycled aggregates carbonated, CC- Exposure to carbonation chamber.

Wsat. Then, specimens were subjected to an standard oven at $105{ }^{\circ} \mathrm{C}$ until the specimens were dried (reaching to a constant mass) and it is dried mass of the specimens, Wdry. Absorption coefficient (A\%) was determined for all the specimens through following (Eq. (2)):

$A(\%)=\frac{\text { Wsat }- \text { Wdry }}{\text { Wsat }- \text { Wim }} \times 100$
The water absorption by capillary method was performed according to the EN 1015-18 standard using three cubic specimens with a $100 \mathrm{~mm}$ edge per mixture. Prior to the water absorption by capillarity, the surface area of the specimens were coated with silicon (except for failure surface resulted from flexural test) in order to assure the water can be absorbed from one surface of the specimens that is soaked in water. The assessmet of the absorbed water was performed by
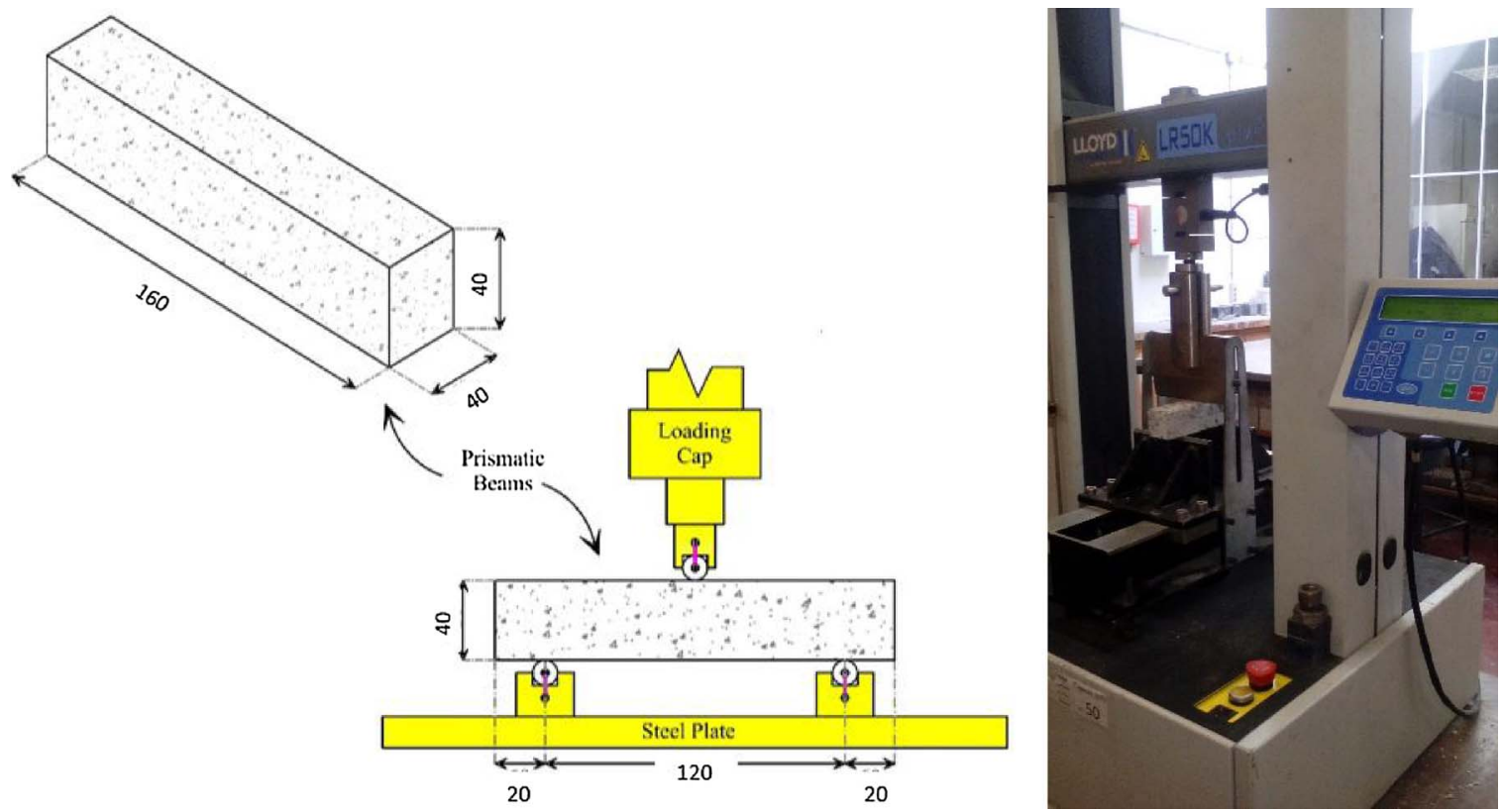

Fig. 3. Adopted test setup for implementation of the flexural test. 
conducting weightings of the specimens through several segment intervals which started at $0 \mathrm{~min}, 5 \mathrm{~min}, 10 \mathrm{~min}, 20 \mathrm{~min}, 30 \mathrm{~min}, 60 \mathrm{~min}$, $90 \mathrm{~min}, 120 \mathrm{~min}, 180 \mathrm{~min}, 240 \mathrm{~min}, 300 \mathrm{~min}, 360 \mathrm{~min}, 1440 \mathrm{~min}$ and $2880 \mathrm{~min}$. However, it should be mentioned that, in order to assess the evolution of the water absorption towards weight stabilization, periodic measurements were performed for about 4days. The capillary coefficient was determined according to Eq. (3):

$C=\frac{M 2-M 1}{\sqrt{t f-t i}}$

In which, $C$ is the capillary absorption coefficient $\left(\mathrm{kg} /\left(\mathrm{m}^{2} . \mathrm{min}^{0.5}\right)\right) ; M 2$ is the weight if the specimen in contact with water at the instant $10 \mathrm{~min}$ $\left(\mathrm{kg} / \mathrm{m}^{2}\right) ; M 1$ is the weight if the specimen in contact with water at the instant of $90 \mathrm{~min}\left(\mathrm{~kg} / \mathrm{m}^{2}\right)$; $t f$ is the final time, instant of $90 \mathrm{~min}(\mathrm{~min})$; and $t i$ is the initial time, instant of $10 \mathrm{~min}$ ( $\mathrm{min}$ ).

\subsubsection{Elastic modulus}

Regarding the ASTM C469 recommendation, three cylinders with $50 \mathrm{~mm}$ diameter and $100 \mathrm{~mm}$ height were submitted by the compressive loading to define the elastic modulus of the different mixtures. The flexural strength of each mixture was obtained by averaging the three specimens. The apparatus consisted of two aluminum rings with screws for attachment to the specimen and three Linear Variable Differential Transformer (LVDT) of $50 \mathrm{~mm}$ stroke used to record displacements around the cylinders. To obtain the elastic modulus, the specimens were subjected by a cyclic compressive load up to $40 \%$ the compressive strength.

\subsubsection{Drying shrinkage}

With respect to the ASTM C596-09 recommendation, three prismatic beams with dimension $25 \times 25 \times 305 \mathrm{~mm}$ were cast and prepared for each mixture to assess the rate of drying shrinkage. After demolding, the beams were cured in a carbonation chamber through a flow $\mathrm{CO}_{2}$ gas. In the present study, Graff-Kaufman method was employed to record the length variations of prismatic beams after demolding. Employing this method eliminates early registration of length changes. Two steel snails were installed at both end sides of the beams to measure length changes of specimens. An installed steel snail was mounted in a fixed steel base and the other steel snail (for the other side) was installed in a digital gauge with the accuracy of $0.001 \mathrm{~mm}$, as shown in Fig. 5. The drying shrinkage rates for the mixtures were measured for more than 40 days. Stabilization of the length variations was taken into account as the main criterion to stop the shrinkage test.

\section{Results and discussion}

\subsection{Compressive strength}

Fig. 4 shows the compressive strength of different mixtures. The maximum compressive strength was found to be around $10 \mathrm{MPa}$ in the mixture 80FA_10CH_10MG_RAGC_CC_8 M. Although this mechanical level is insufficient for high strength applications in the construction industry is still sufficient for the production of masonry blocks. The results also show that regardless of the mixture type and curing age, increasing the molarity from $7 \mathrm{M}$ to $8 \mathrm{M}$ increased the compressive strength. The maximum increase of the compressive strength was measured in the mixture 80FA_10CH_10MG_RAGC_CC_8 M with about $60 \%$, as compare to 80FA_10CH_10MG_RAGC_CC_7 M. Several authors already reported that a high concentration of sodium hydroxide from leads to an increase in the coagulation of silica and a reduction on the compressive strength (Rattanasak and Chindaprasirt, 2009; Gorhan and Kurklu, 2014; Atis et al., 2015). In general the replacement of Portland cement by calcium hydroxide is associated with an increase in the compressive strength. The explanation could be associated to the fact that replacement may lead to the formation of a higher amount of CSH gel. This is because of the low sodium hydroxide concentration used in the present study (Garcia-Lodeiro et al., 2016) that favour CSH formation. Since no consistent trend for the compressive strength was found due to increasing the molarity from $8 \mathrm{M}$ to $9 \mathrm{M}$. For instance, the compressive strength increased around $30 \%$ for the mixture 80FA_10PC_10MG_ RAGC_CC at the age of 7 days by increasing the molarity from $8 \mathrm{M}$ to $9 \mathrm{M}$, while the compressive strength was decreased about $15 \%$ for the mixture 80FA_10CH_10MG_RAGC_CC. The explanation for the compressive strength loss with high sodium hydroxide concentration from $8 \mathrm{M}$ to $9 \mathrm{M}$ is not related to an increase in leaching of the amount of silica and alumina species from fly ash (Sata et al., 2013; Hanjitsuwan et al., 2014) because that explanation is only valid for sodium hydroxide concentrations above $10 \mathrm{M}$ that lead to the formation of aluminosilicate species (Alonso and Palomo, 2001a,b). Increasing the duration of curing also increased the compressive strength, so that the maximum compressive strength for the specimens at the age of 14 days was measured around $9 \mathrm{MPa}$ in the mixture 80FA_10CH_10MG_ RAGC_CC_8 M. Furthermore, no variation in the tendency of the compressive strength of mixtures was detected due to increase of curing duration from 14 to 28 days. Interestingly, it was found the maximum compressive strength at the early age (7 days for the mixture of 80FA_10CH_10MG_RAGC_CC_8 M) was about $70 \%$ of the compressive strength at the final age (28 days).

\subsection{Flexural strength}

Fig. 5 illustrates the results obtained for the flexural strength. Similar to the results obtained for the compressive strength, the maximum flexural strength was detected in the mixture containing the sodium hydroxide with the molarity of $8 \mathrm{M}$, so that the maximum flexural strengths around 3.5 and $2.5 \mathrm{MPa}$ were recorded for the mixtures of 80FA_10CH_10MG_RAGC_CC_8 M and 80FA_10PC_10MG_RAGC_CC_ $8 \mathrm{M}$, respectively. Increasing the molarity from $7 \mathrm{M}$ to $8 \mathrm{M}$ increased about $75 \%$ and $210 \%$ the flexural strength of the mixtures 80FA_10CH_10MG_RAGC_CC and 80FA_10PC_10MG_RAGC_CC, respectively. While increasing the molarity from $8 \mathrm{M}$ to $9 \mathrm{M}$ reduced about $10 \%$ and $45 \%$ the flexural strength of the mixtures 80FA_10CH_10MG_RAGC_CC and 80FA_10PC_10MG_RAGC_CC, respectively. Fig. 6 shows the correlation between the flexural strength and the compressive strength of the mixtures, consisting high coefficient of determination. $\mathrm{F}_{\mathrm{r}}$ represents the flexural strength. With respect to the developed equations, the rate of improving the mechanical properties of the mixtures 80FA_10CH_10MG_RAGC_CC was higher, as compared to the mixtures 80FA_10PC_10MG_RAGC_CC.

\subsection{Water absorption}

Fig. 7 is depicted the results of water absorption by immersion and density. The minimum water absorption of around $9.4 \%$ is noticed for the mixtures with a sodium hydroxide concentration of $8 \mathrm{M}$ the ones that were associated to a higher compressive strength. No relevant differences were noticed when calcium hydroxide was replaced by Portland cement. An increase of the sodium hydroxide concentration from $7 \mathrm{M}$ to $8 \mathrm{M}$ lead to a water absorption reduction of $5 \%$ and $10 \%$ for the mixtures based on OPC and calcium hydroxide, respectively. As to the reduction from $8 \mathrm{M}$ to $9 \mathrm{M}$ a minor water absorption increase was noticed of $5 \%$ and $3 \%$ for the mixtures based on OPC and calcium hydroxide, respectively. The minimum and maximum density were recorded in the mixture consist of sodium hydroxide with concentrations of $7 \mathrm{M}$ (80FA_10PC_10MG_ RAGC_CC_7 M with density of $2172 \mathrm{~kg} / \mathrm{m}^{3}$ and 80FA_10CH_10MG_RAGC_CC_7 M with density of $\left.2144 \mathrm{~kg} / \mathrm{m}^{3}\right)$ and $8 \mathrm{M}\left(80 \mathrm{FA} \_10 \mathrm{PC} 10 \mathrm{MG}\right.$ _ RAGC_CC_8 M with density of $2210 \mathrm{~kg} / \mathrm{m}^{3}$ and 80FA_10CH_10MG_RAGC_CC_8 M with density of $2258 \mathrm{~kg} / \mathrm{m}^{3)}$, respectively. Fig. 8 depicts the capillary water absorption coefficients. Regardless the concentration of the sodium hydroxide, replacing calcium hydroxide by OPC is associated to a reduction of the 


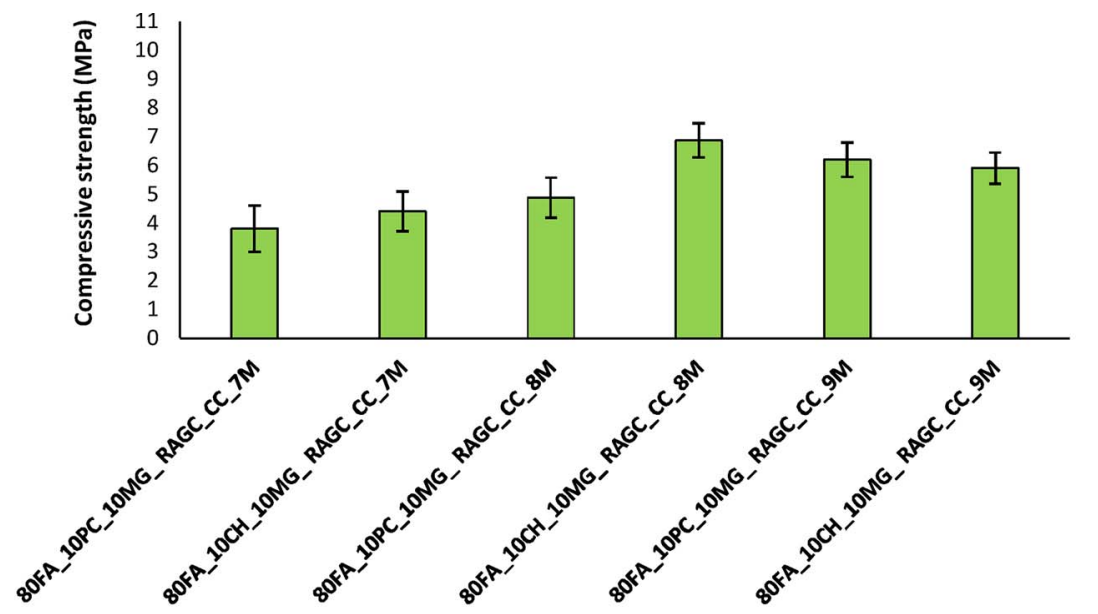

Fig. 4. The compressive strength of the mixtures cured for: a) 7 days; b) 14 days; c) 28 days.

a)

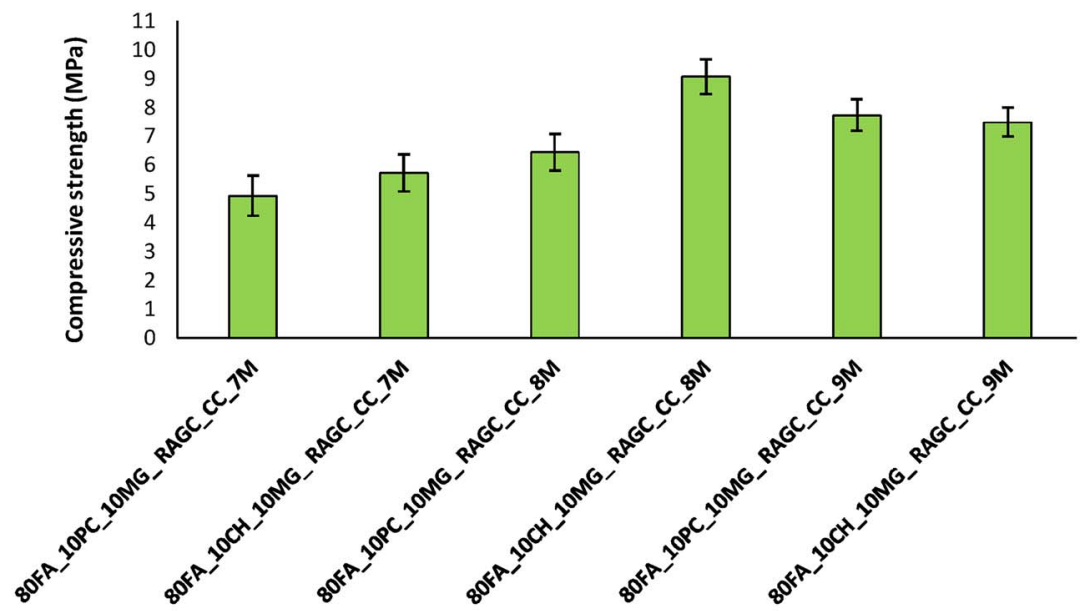

b)

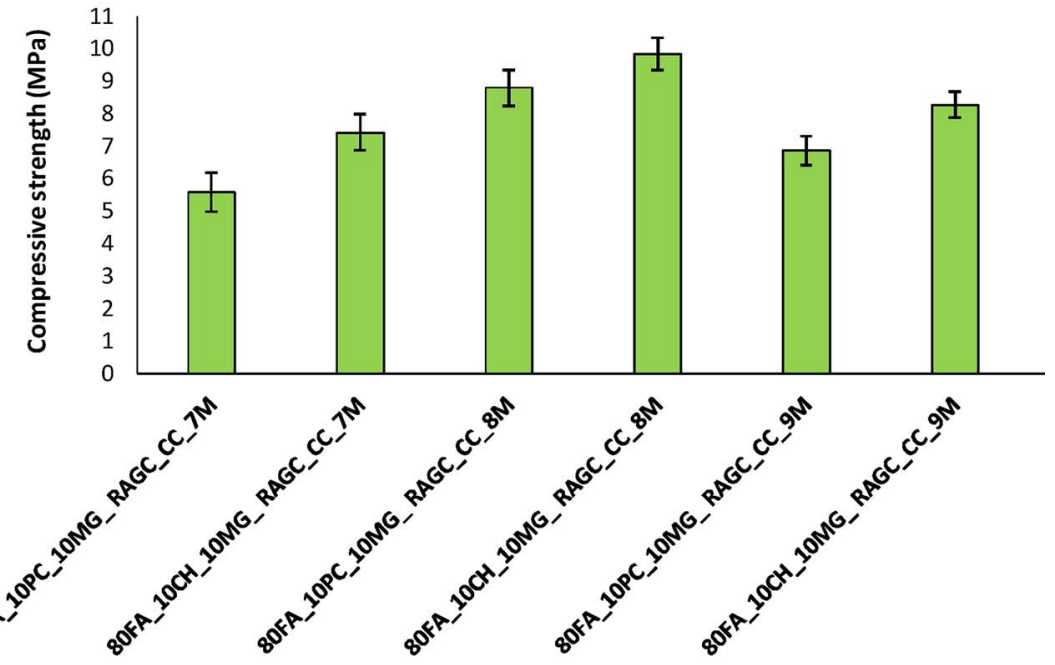

c)

capillary water absorption coefficients. The maximum reduction was measured more than $40 \%$ in the mixture containing the molarity $8 \mathrm{M}$. This coefficient was varied in the range of $1.45-2 \mathrm{~kg} / \mathrm{m}^{2} . \mathrm{H}^{0.5}$ for the mixtures containing calcium hydroxide, while this interval changed in the range of $2.51-2.88 \mathrm{~kg} / \mathrm{m}^{2} . \mathrm{H}^{0.5}$ for the mixtures used OPC. Since the tendency of mixtures to absorb and transmit water by capillary action in the plain mixture could be functioned by the capillary network, porosity and tortuosity in the matrix this means that the use of calcium hydroxide is associated to a denser microstructure. Abdollahnejad et al. (2017) also studied alkaline based mixtures reporting water absorption capillarity coefficients in the range of $2.25-4 \mathrm{~kg} / \mathrm{m}^{2} . \mathrm{H}^{0.5}$ where a lower OPC content was associated with higher values. Since lower capillarity 


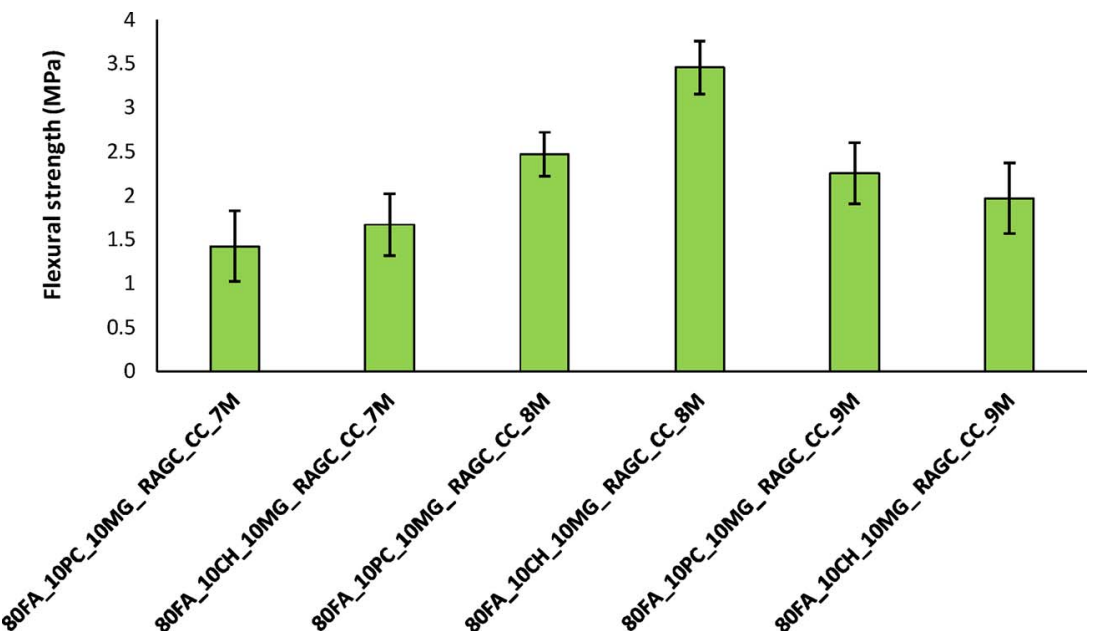

Fig. 5. Flexural strength.

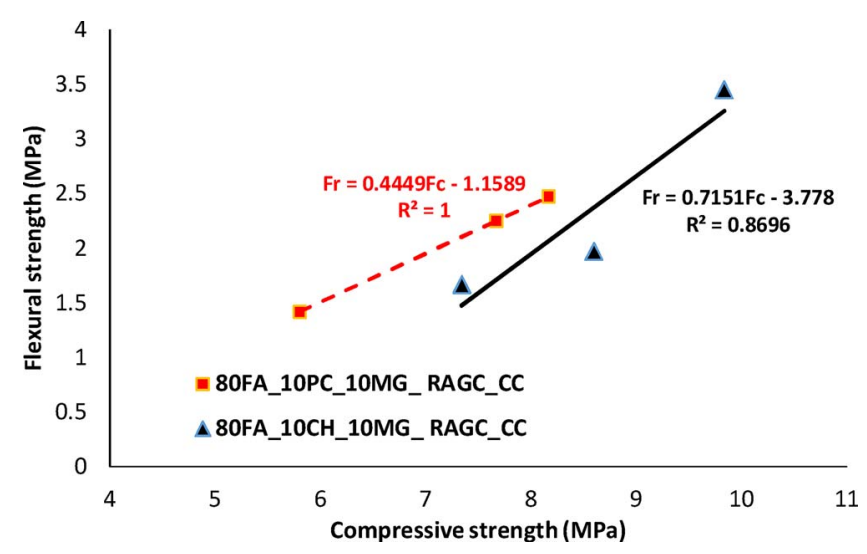

Fig. 6. Correlation between the compressive strength and the flexural strength.

coefficients were reported in this study for mixtures with minor amount of calcium hydroxide its possible that the accelerated carbonation curing has been responsible for a coarser capillarity network.

\subsection{Elastic modulus}

The results of the elastic modulus are shown in Fig. 9. Regarding the results, increasing the sodium hydroxide molarity increased the stiffness of the mixtures, so that the maximum elastic modulus was recorded in the mixtures containing a sodium hydroxide equal to $9 \mathrm{M}$.
Moreover, it was detected that using $\mathrm{CH}$ instead of PC increased the elastic modulus of the mixtures, regardless of the molarity. Therefore, the maximum elastic modulus was measured around $800 \mathrm{MPa}$ in the mixture of 80FA_10CH_10MG_ RAGC_CC_9 M. For the mixtures of 80FA_10PC_10MG_RAGC_CC, the maximum increase of the elastic modulus was recorded $66 \%$ due to increase of the molarity from $7 \mathrm{M}$ to $8 \mathrm{M}$. Since for the mixtures of 80FA_10CH_10MG_RAGC_CC, the maximum increase of the elastic modulus was achieved 13\% due to increase of the molarity from $8 \mathrm{M}$ to $9 \mathrm{M}$. As indicated in Fig. 10, where, $\mathrm{E}$ is the elastic modulus and $\mathrm{F}_{\mathrm{C}}$ is the compressive strength. The analytical results arise from correlation between elastic modulus and the compressive strength revealed that the elastic modulus increases the compressive strength with higher rate in the mixture based on OPC than in the mixture with calcium hydroxide. Also a significant correlation was found in the mixture based on OPC but not relevant correlation was found for the mixture based on calcium hydroxide. Moreover, it was found that of 80FA_10PC_10MG_RAGC_CC, when compared to the mixture of 80FA_10CH_10MG_RAGC_CC.

\subsection{Drying shrinkage}

The drying shrinkage results are depicted in Fig. 11. Regardless of the mixture and concentration of sodium hydroxide, the rates of drying shrinkages were characterized by higher initial growth, reaching approximately $50 \%$ of the total drying shrinkage rate at the first 7 days for the majority of the mixtures. The minimum and maximum rates of drying shrinkage was recorded in the mixtures 80FA_10CH_10MG_RAGC_CC_8 M $(0.0131 \mu \varepsilon)$ and

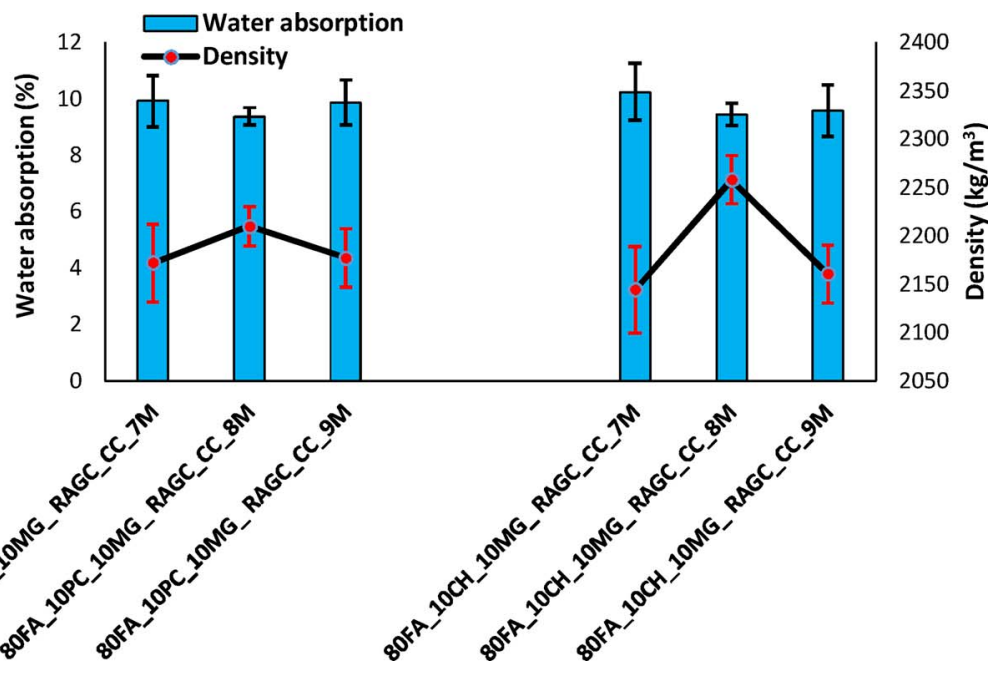

Fig. 7. Water absorption vs. density. 


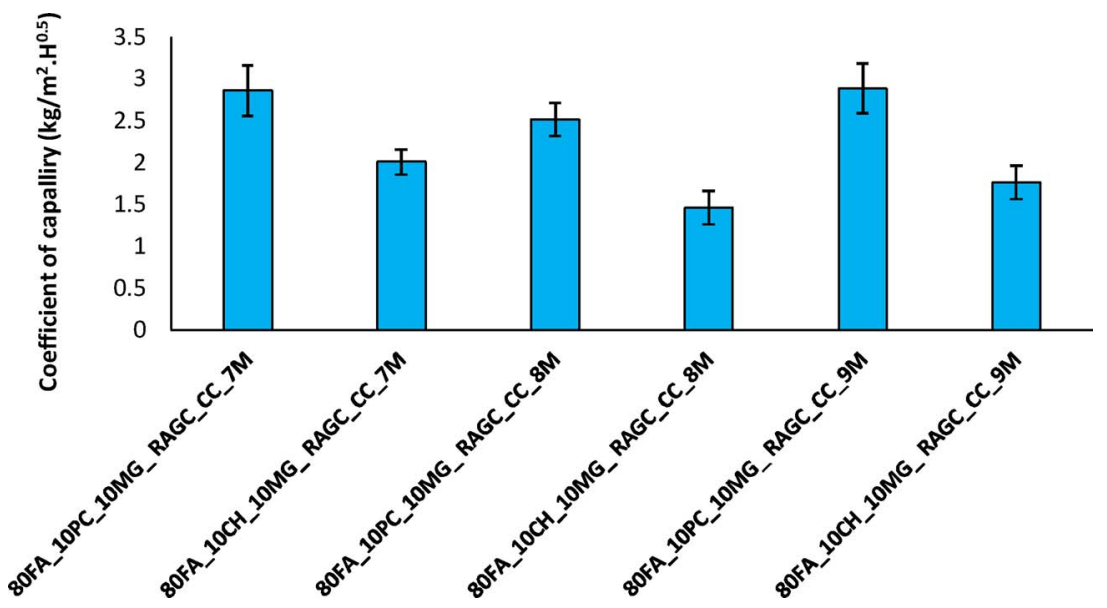

Fig. 8. Capillary water absorption coefficient.

80FA_10CH_10MG_RAGC_CC_9 M $(0.0231 \mu \varepsilon)$, respectively. Moreover, the minimum rate of drying shrinkage for the mixture 80FA_10CH_10MG_RAGC_CC was measured by sodium hydroxide concentration of $8 \mathrm{M}$. Regardless of the mixture type, the maximum rate of drying shrinkage was recorded in the mixtures containing the molarity of $7 \mathrm{M}$. The results can be partially explained by the results of the modulus of elasticity because mixtures with a lower stiffness have a higher shrinkage Also this results are in line with the capillary water absorption and can be explained by the fact that finer capillary networks are associated to a higher capillary stress that generates shrinkage.

\section{6. $\mathrm{CO}_{2}$ sequestration}

Fig. 12 depicts the results of $\mathrm{CO}_{2}$ sequestration. The results, show that for mixtures that contain PC increasing sodium hydroxide molarities from $7 \mathrm{M}$ to $9 \mathrm{M}$ consistently increased the amount of the $\mathrm{CO}_{2}$ sequestration. However, when the mixtures are compared for the same sodium hydroxide concentration no differences are detected for both $7 \mathrm{M}$ based mixtures $\left(130 \mathrm{kgCO}_{2} \mathrm{eq} / \mathrm{m}^{3}\right)$ or even for both $9 \mathrm{M}$ based mixtures $\left(152 \mathrm{kgCO}_{2} \mathrm{eq} / \mathrm{m}^{3}\right)$. For mixtures based on calcium hydroxide the maximum $\mathrm{CO}_{2}$ sequestration $\left(164 \mathrm{kgCO}_{2} \mathrm{eq} / \mathrm{m}^{3}\right)$ is noticed for the mixture with a sodium concentration of $8 \mathrm{M}$. Since the diffusivity of $\mathrm{CO}_{2}$ in alkali-activated materials is controlled by the same variables as identified in conventional Portland cements namely the porosity and permeability of the material and since this mixture does not have a higher water capillary coefficient (which is a proxy of permeability) then the higher carbon sequestration capacity of these mixture must be associated to a higher content of $\mathrm{CSH}$ that were carbonated. Other

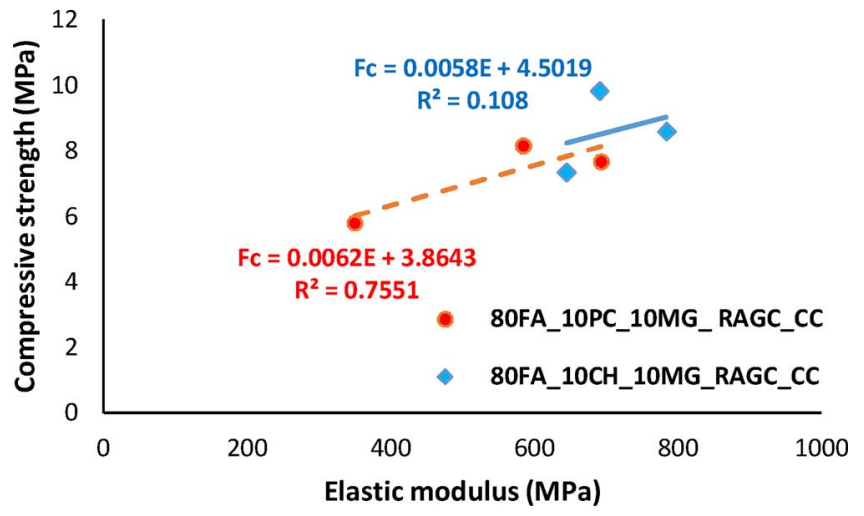

Fig. 10. Correlation between the compressive strength and elastic modulus.

authors (El-Hassan and Shao, 2014) have studied the $\mathrm{CO}_{2}$ sequestration using accelerated $\mathrm{CO}_{2}$ curing in the concrete blocks containing $13 \%$ OPC reporting a sequestration of $75 \mathrm{kgCO}_{2} \mathrm{eq} / \mathrm{m}^{3}$. This means that alkali-activated materials have a higher carbon sequestration capacity.

\section{Conclusions}

The mixtures with calcium hydroxide and sodium hydroxide concentration of $8 \mathrm{M}$ leads to the highest compressive strength (10 MPa) which is high enough for the production of masonry blocks.

The results show that the replacement of Portland cement by calcium hydroxide is associated with an increase in the compressive

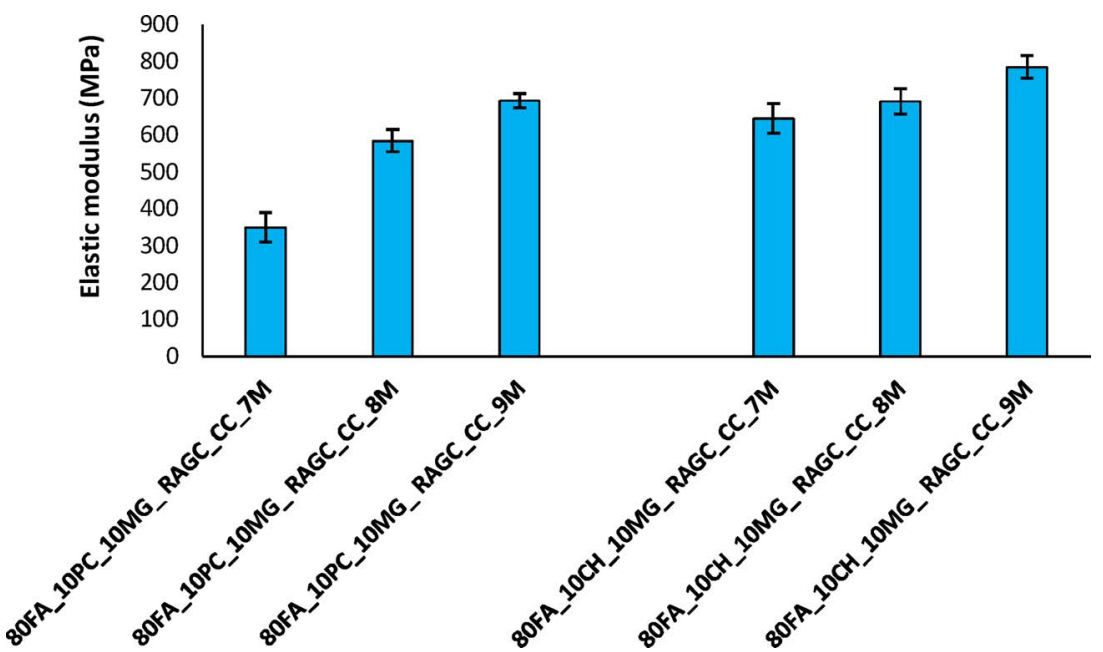

Fig. 9. Elastic modulus. 


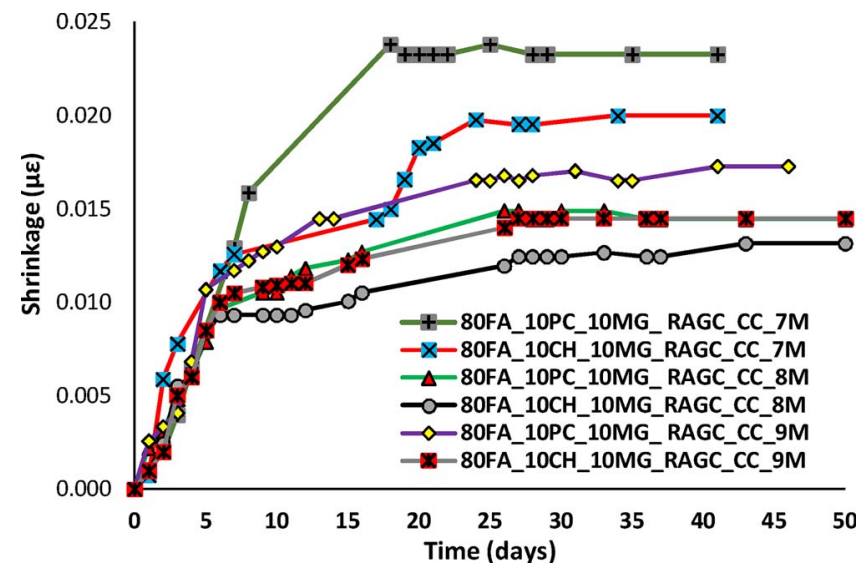

Fig. 11. Drying shrinkage.

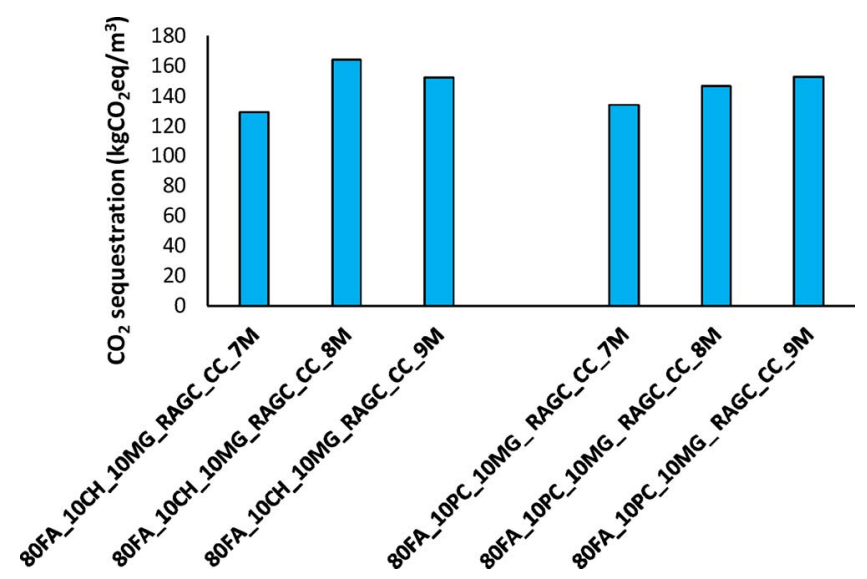

Fig. 12. $\mathrm{CO}_{2}$ sequestration.

strength due to the formation of a higher amount of CSH gel. The maximum flexural strength is 3,5 MPa. Significant correlations between the flexural strength and the compressive strength were noticed. The mixtures show a low water absorption by immersion (9\%) as well as by capillary $\left(1.4 \mathrm{~kg} / \mathrm{m}^{2} . \mathrm{H}^{0.5}\right)$ and its possible that the accelerated carbonation curing has been responsible for a coarser capillarity network. The results of the modulus of elasticity show that increasing the sodium hydroxide molarity increased the stiffness of the mixtures. Also a significant correlation between elastic modulus and compressive strength was found in the mixture based on OPC. The results of drying shrinkage are in line with the results of the capillary water absorption and of elastic modulus. A maximum $\mathrm{CO}_{2}$ sequestration $\left(164 \mathrm{kgCO}_{2} \mathrm{eq} / \mathrm{m}^{3}\right)$ is noticed for the mixture with a sodium concentration of $8 \mathrm{M}$ based on the additive calcium hydroxide.

\section{Acknowledgment}

The authors would like to acknowledge the financial support of the Foundation for Science and Technology (FCT) in the frame of project IF/00706/2014-UM.2.15.

\section{References}

American Coal Ash Association, 2016. https://www.acaa-usa.org/Publications/ Production-Use-Reports.

ASTM C109/C109M-16a, Standard Test Method for Compressive Strength of Hydraulic Cement Mortars (Using 2-in. or [50 mm] Cube Specimens), ASTM International, West Conshohocken, PA, 2016, www.astm.org.

ASTM C618-15, Standard Specification for Coal Fly Ash and Raw or Calcined Natural Pozzolan for Use in Concrete, ASTM, International, West Conshohocken, PA, 2015, www.astm.org.

Abdollahnejad, Z., Miraldo, S., Pacheco-Torgal, F., Barroso Aguiar, J., 2017. Cost-efficient one-part alkali-activated mortars with low global warming potential for floor heating systems applications. Eur. J. Environ. Civil Eng. 21, 412-429.

Alonso, S., Palomo, A., 2001a. Calorimetric study of alkaline activation of calcium hydroxide-metakaolin solid mixtures. Cem. Concr. Res. 31, 25-30.

Alonso, S., Palomo, A., 2001b. Alkaline Activation of metakaolin and calcium hydroxide mixtures: influence of temperature, activator concentration and solids ratio. Mater. Lett. 47, 55-62.

Atis, C.D., Görür, E.B., Karahan, O., Bilim, C., Ilkentapar, S., Luga, E., 2015. Very high strength $(120 \mathrm{MPa})$ class $\mathrm{F}$ fly ash geopolymer mortar activated at different $\mathrm{NaOH}$ amount, heat curing temperature and heat curing duration. Constr. Build. Mater. 96, 673-678.

Bernal, S., Rodríguez, E., Kirchheim, A., Provis, J., 2016. Management and valorisation of wastes through use in producing alkali-activated. Cement materials. J. Chem. Technol. Biotechnol. http://dx.doi.org/10.1002/jctb.4927.

Bontempi, E., 2017a. A new approach for evaluating the sustainability of raw materials substitution based on embodied energy and the CO 2 footprint. J. Clean. Prod. 162, 162-169.

Bontempi, E., 2017b. A new approach to evaluate the sustainability of raw materials substitution. Raw Materials Substitution Sustainability. Springer, Cham, pp. 79-101.

El-Hassan, H., Shao, Y., 2014. Carbon storage through concrete block carbonation. J. Clean Energy Technol. 2, 287-291.

El-Hassan, H., Shao, Y., 2015. Early carbonation curing of concrete masonry units with Portland limestone cement. Cem. Concr. Compos. 62, 168-177.

Garcia-Lodeiro, I., Donatello, S., Fernandez-Jimenez, A., Palomo, A., 2016. Hydration of hybrid alkaline cement containing a very large proportion of fly ash: a descriptive Model. Material 9, 605.

Gorhan, G., Kurklu, G., 2014. G.The influence of the NaOH solution on the properties of the fly ash-based geopolymer mortar cured at different temperatures. Compos. Pt. B 58, 371-377.

Hanjitsuwan, S., Hunpratub, S., Thongbai, P., Maensiri, S., Sata, V., Chindaprasirt, P., 2014. Effects of $\mathrm{NaOH}$ concentrations on physical and electrical properties of high calcium fly ash geopolymer paste. Cem. Concr. Compos. 45, 9-14.

Hansen, J., Sato, M., Kharecha, P., von Schuckmann, K., Beerling, D.J., Cao, J., Marcott, S., Masson-Delmotte, V., Prather, M.J., Rohling, E.J., Shakun, J., Smith, P., 2017. Young people's burden: requirement of negative CO2 emissions. Earth Syst. Dynam. Discuss. http://dx.doi.org/10.5194/esd-2016-42.

Hossain, M.U., Poon, C.S., Lo, I.M., Cheng, J.C., 2016. Comparative environmental evaluation of aggregate production from recycled waste materials and virgin sources by LCA. Resour. Conserv. Recycl. 109, 67-77.

Huang, T.Y., Chiueh, P.T., Lo, S.L., 2016. Life-cycle environmental and cost impacts of reusing fly ash. Resour. Conserv. Recycl.

Ioannidou, D., Meylan, G., Sonnemann, G., Habert, G., 2017. Is gravel becoming scarce? Evaluating the local criticality of construction aggregates. Resour. Conserv. Recycl. 126, 25-33.

Jang, J.G., Kim, G.M., Kim, H.J., Lee, H.K., 2016. Review on recent advances in $\mathrm{CO}_{2}$ utilization and sequestration technologies in cement-based materials. Constr. Build. Mater. 127, 762-773.

Mote, C., Dowling, J., Zhou, J., 2016. The power of an idea: the international impacts of the grand challenges for engineering. Engineering 2, 4-7.

Pacheco-Torgal, F., Tam, V., Labrincha, J., Ding, Y., de Brito, J. (Eds.), 2013. Handbook of Recycled Concrete and Demolition Waste. Elsevier, Cambridge.

Poinot, T., Laracy, M.E., Aponte, C., Jennings, H.M., Ochsendorf, J.A., Olivetti, E.A., 2018. Beneficial use of boiler ash in alkali-activated bricks. Resour. Conserv. Recycl. $128,1-10$.

Rattanasak, U., Chindaprasirt, P., 2009. Influence of $\mathrm{NaOH}$ solution on the synthesis of fly ash geopolymer. Miner. Eng. 22, 1073-1078.

Šavija, B., Luković, M., 2016. Carbonation of cement paste: understanding, challenges, and opportunities. Constr. Build. Mater. 117, 285-301.

Sata, V., Wongsa, A., Chindaprasirt, P., 2013. Properties of pervious geopolymer concrete using recycled aggregates. Constr. Build. Mater. 42, 33-39.

Torres-Carrasco, M., Puertas, F., 2017. Waste glass as a precursor in alkaline activation: chemical process and hydration products. Constr. Build. Mater. 139, 342-354.

Van Deventer, J., Provis, J., Duxson, P., Brice, D., 2010. Chemical research and climate change as drivers in the commercial adoption of alkali activated materials. Waste Biomass Valor 1, 145-155.

Zhang, Z., Huisingh, D., 2017. Carbon dioxide storage schemes: technology, assessment and development. J. Clean. Prod. 142, 1055-1064. 